\title{
Palliative care, animal assisted-activity and autonomy
}

\begin{abstract}
Despite the advances in medicine, curing a patient is not always possible. There are cases when patients are terminal. In such cases, doctors have a duty of care and to try to lessen their patients' pain and suffering. Treating pain must be seen as the issue to be addressed by medicine. This realm encompasses palliative care, meant to palliate, allay, and ease suffering and make patients comfortable. Added to that is animal-assisted activity, a low-cost technique scientifically proven to make patients feel better. Whether in the case of animal-assisted activity or any other intervention, patients must always be asked what they would like to be done and have their wishes respected.
\end{abstract}

Keywords: palliative care, animal-assisted activity, autonomy
Volume 3 Issue 2 - 2019

\author{
Anelise Crippa \\ Researcher, Biomedical Gerontology, Pontifical Catholic \\ University of Rio Grande do Sul, Brazil
}

Correspondence: Anelise Crippa, Attorney-at-law, Researcher, Biomedical Gerontology PhD, Pursuing a post-doctoral degree in Law at Pontifical Catholic University of Rio Grande do Sul, Brazil, Email anecrippa@gmail.com

Received: January 10, 2018 | Published: March 15, 2019

\section{Introduction}

Over time, medical progress and technology development have allowed humans to live longer. However, we all know people are finite and a cure is not always possible.

When we face a disease that can no longer be cured, we seek through palliate care to make patients feel as comfortable and well as possible. In this case, we are dealing with terminal people. Palliative care is used in a wide range of fields to lessen pain and suffering.

Pain and suffering deserve to be relevant in the medical field, more so in terms of palliative care. Seeking procedures to lessen pain and provide comfort is paramount.

Paired with the search for palliative measures that provide wellbeing, there is a renowned method popular in several places around the world, such as European countries and the US, which is yet to gain wider acceptance in Brazil. This method comprises bringing animals into hospitals through animal-assisted activity. The animal's interaction with patients gets the latter to feel better and eases their suffering.

\section{Animal assisted-activity}

Animal-assisted activity uses animals to mitigate suffering and help patients feel better. In some cases, it helps improve treatment, when improvement is still possible. It first appeared in England in 1792, at a psychiatric clinic.

The activity is carried out with the aid of volunteers. The animals used are trained, worm-free, vaccinated, bathed 24 hours in advance, and cleared by a vet attesting to their health. The animals most often used are dogs. Dogs are also seen in other fields besides healthcare, such as in police operations and fire fighting squads, and as seeingeye dogs. ${ }^{1}$ Other animals can be used as well, such as cats, rabbits, birds, and Guinea pigs, to name a few. ${ }^{2}$ Location-wise, visits can take place at hospitals, in patient rooms, or community areas. This is an important matter in order to respect patients' autonomy, because those who are unwilling to participate in the activity must not be forced to join in.

Something so simple and whose efficacy is widely acknowledged are having a hard time getting accepted by Brazilian medicine. Few are the hospitals where it is allowed. In some cases, the very hospital personnel know very little about it. However, surveys at a hospital in southern Brazil have shown patients wish to get affection from animals. ${ }^{3}$ Why not include something so beneficial and low-cost?
Using animals in human life has been seen often throughout the history of humankind. US philosopher Bernard Rollin ${ }^{4}$ claims the relationship between animals and humans has been going on since the beginning of humankind.

\section{Patient autonomy}

Patients must have their autonomy preserved. Just because someone is terminal it does not mean they should be denied this right and ethical principle. Patients' free, informed consent must be given for any sort of palliative intervention to take place.

Respect for patient autonomy is one of the principles of bioethics. When it comes to the principle of respecting one's autonomy, such principle corresponds to the involved person's self-determination to accept their ability to decide what they think is best for themselves. This principle gives patients room to express their wishes regarding the prescribed treatments.

Healthcare professionals must respect those who do not wish to have contact with animals, who do not like animals or simply do not want any around. Patients must not be pushed or coaxed, not even towards something simple that could make them feel better. Decisions are the patients' to make, not their medical team's or family's. Decision-making involves several factors, and patients need to understand and evaluate it.

\section{Conclusion}

Healthcare professionals must look at the models that work and make people feel better, and allow them to do as they wish. Countries like Brazil, which are yet to fully accept models like animal-assisted activity, should rid themselves of their biases and realize the benefits palliative care patients may derive. The quest should be one of wellbeing, respect, and preserved dignity, even though it may take breaking down paradigms and conventional barriers.

\section{Acknowledgments}

None.

\section{Conflicts of interest}

The author declares there is no conflict of interest.

\section{References}

1. Willis MB. Genetic aspects of dog behaviour with particular reference to working. In: Serpell J, editor. The domestic dog: its evolution, 
behavior and interactions with people. London: Cambridge University Press; 1995:1-284.

2. Crippa A, Feijó AGS. Actividad Assistida por Animales. Rev Latinoam Bioet. 2014;14(1):14-25.
3. Crippa A, Costa GC, Feijó AGS. Atividade Assistida por Animais na Pediatria. Revista da Amrigs Porto Alegre. 2015;59(3):243-247.

4. Rollin B. Animal rights and human morality. New York: Prometheus Books; 1981. 